\title{
PREDATION OF BLUEBIRDS BY AN EASTERN CHIPMUNK
}

\author{
by Wayne Miller, 2 Almond Crescent, Brandon, Manitoba
}

On June 29, 1968, five miles east of Carberry, Manitoba, members of the Brandon Junior Bird Club and I observed the predation of an Eastern Bluebird brood (Sialia sialis) by an Eastern Chipmunk (Tamias striatus).

The nesting box was located five feet from the ground on top of a rough fence post. At its base was a ledge upon which the chipmunk had gained a footing to enter the box. The diameter of the entrance was an inch and a half.

Of the bluebird pair present, the male was the more aggressive in nest defence. His defence mechanisms included (1) the hovering display (after Lack, 1946), (2) attacking (this was repeated until the chipmunk was driven from the box), and, (3) defence vocalizations (consisting of "chirr", "chichip"), and mechanical defence (or bill snapping). The hovering display and the territorial song were used as assurance to the female bird.

The female bluebird's defence con- sisted of flying several times to the top of the nesting box, and perching below the nest between these flights. Nest defence was observed only when the chipmunk was within the box. After the intruder had been driven away, both birds perched just below the box and examined the ground for nearly five minutes.

We examined the contents of the nest and found that the chipmunk had killed two of the five four-day-old young, and had begun to devour their remains. When we left the nesting area, the bluebirds again perched below the nest, watching for the intruder.

Although predation of birds by an Eastern Cnipmunk is in itself unusual, the fact that a nesting box was entered in this instance is of particular interest. This is the first time the Brandon Junior Birders have recorded such behavior for the species.

\section{Literature Cited}

Lack, D. 1946. The Life of the Robin.

R. F. and G. Witherby, London.

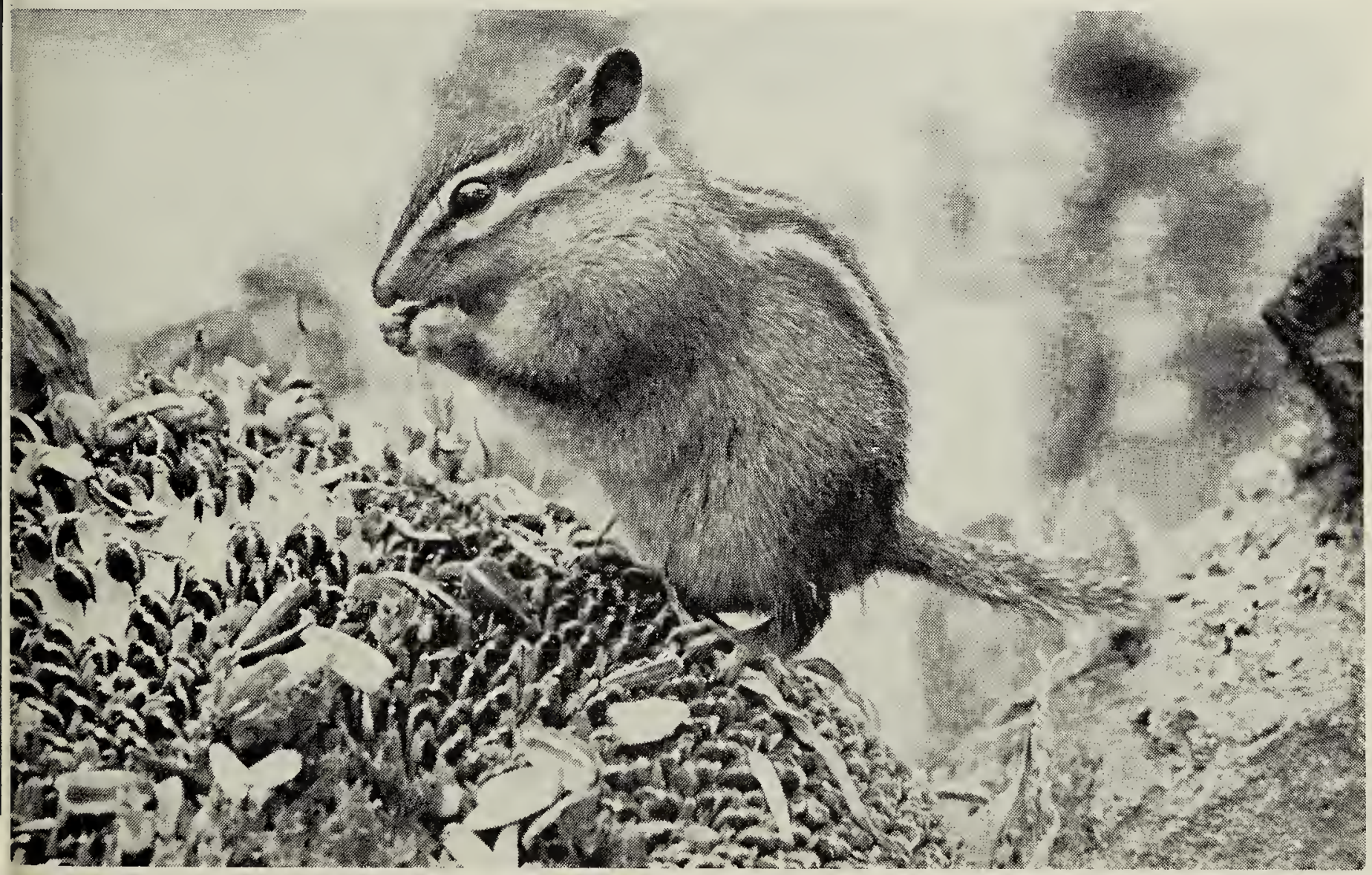

